\title{
Thiourea Catalysis via Anion Binding
}

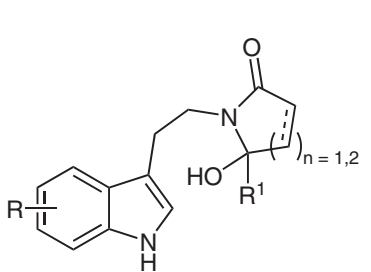

$\mathrm{R}=\mathrm{H}, \mathrm{OMe}, \mathrm{Br}, \mathrm{F}, \mathrm{Me}$

$\mathrm{R}^{1}=\mathrm{H}, \mathrm{Me}, n-\mathrm{Bu}, \mathrm{Ph}$

1

Working

hypothesis:

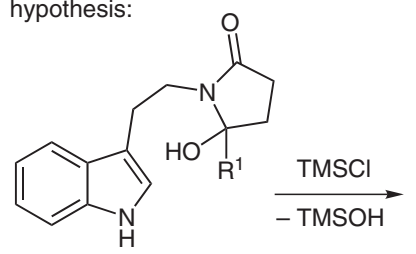

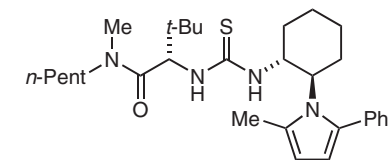

catalyst 2 (10 mol\%), TMSCI

TBME, $-55^{\circ} \mathrm{C}$ or $-78^{\circ} \mathrm{C}, 24-72 \mathrm{~h}$

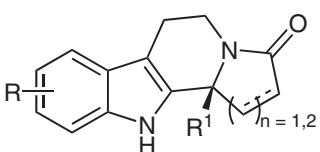

3

15 examples

$51-94 \%$ yield er $=90.5: 9.5$ to $99.5: 0.5$

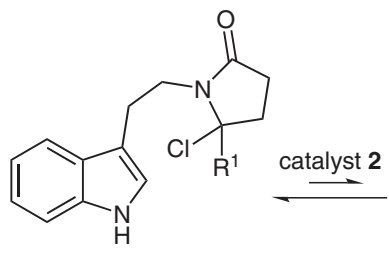

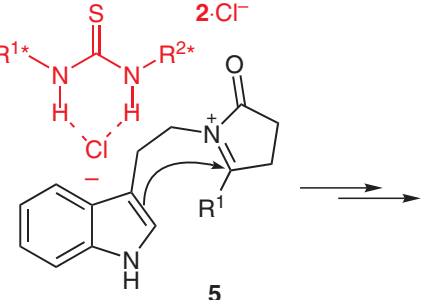

Selected examples:

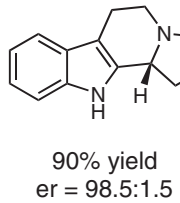

er $=98.5: 1.5$

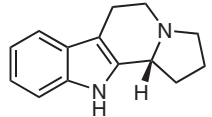

(+)-harmicine er $=98.5: 1.5$ (four steps from tryptamine)

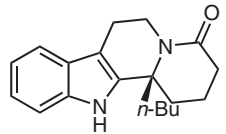

$65 \%$ yield er $=98: 2$

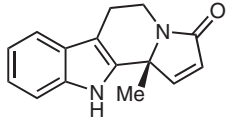

$59 \%$ yield

er $=94: 6$

(with $15 \mathrm{~mol} \% 2$ )
Significance: Asymmetric Pictet-Spengler-type cyclizations of $\beta$-indolyl ethyl hydroxylactams $\mathbf{1}$ have been achieved in the presence of thiourea derivative $\mathbf{2}$ as chiral catalyst. Both indolizidinones $(\mathbf{3}, \mathrm{n}=1)$ and quinolizidinones $(\mathbf{3}, \mathrm{n}=2)$ are obtained in good to excellent yields and optical purities. TMSCl is required for the generation of chlorolactams 4 . Plausibly thiourea catalyst 2 abstracts the chloride from $\mathbf{4}$ generating a chiral $\mathrm{N}$ acyl iminium chloride-thiourea complex $\mathbf{5}$ as reactive intermediate. Subsequent cyclization in the chiral environment provided by the chiral thioureachloride anion complex $\left(\mathbf{2} \cdot \mathrm{Cl}^{-}\right)$leads to enantiomerically enriched products.
Comment: In 2004, Taylor and Jacobsen have discovered Pictet-Spengler-type reactions, which proceed through initial acylation of imines and are promoted by thiourea catalysts of type 2 (J. Am. Chem. Soc. 2004, 126, 10558). In the present study, the Jacobsen group describes a new reaction variant and elucidates the unprecedented reaction mechanism supported by their experimental observations and the well-known anionbinding properties of (thio)ureas. Since the chiral information is exclusively provided by the chiral counteranion $\left(\mathbf{2} \cdot \mathrm{Cl}^{-}\right)$during the enantiodetermining step, this study may be considered a new example of asymmetric counteranion-directed catalysis (S. Mayer, B. List Angew. Chem. Int. Ed. 2006, 45, 4193). 